\title{
Examining the Effects of Cultural Distance and Cultural Intelligence on Students' Overseas Experience
}

\author{
Hang Cheng \\ International Business School \\ Yunnan University of Finance and Economics \\ Kunming, China \\ 541460570@qq.com
}

\author{
Ying Zhang* \\ 1. School of Management and Marketing \\ Charles Sturt University \\ Wagga Wagga, Australia \\ 2. International Business School \\ Yunnan University of Finance and Economics \\ Kunming, China \\ angie@ynufe.edu.cn
}

\begin{abstract}
There is an increasing wave that students are being sent to overseas for either temporary study or global internship by international programs and institutions. This article aims to examine the relationships between components of a multidimensional model of cultural intelligence, and overseas students' social-cultural and psycho-cultural experience in different cultural contexts, with special consideration given to the effects of Cultural Distance on the covered relationships. We proposed that there would be a significant difference among students on adaptability in the case of the extent of their psycho-cultural and social-cultural experience, and that cultural distance would moderate the relationship between the experience of overseas students and their cultural intelligence.
\end{abstract}

Keywords-overseas internship; cultural intelligence; cultural distance

\section{INTRODUCTION}

\section{A. Research Background}

As the Belt and Road Initiative covers over 60 countries, this implies complex educational operations that include such elements as student internship management, student exchange, cross-border experience, safety and security control. The ministry posted statistics on its website on April 13 showing that countries along the Silk Road Economic Belt and the 21st Century Maritime Silk Road, such as India, Pakistan and Kazakhstan, have further grown as large sources of international students in China.

According to the China Study Abroad Development Report 2015, the number of international students keeps increasing, among which the number of students receiving higher education grows more obviously. In $2013 \sim 2014$, in the United States, Britain, China and other eight countries, the number of international students who received higher education was 2921141. The number of international students who received higher education in China achieved 356499 , with the growth rate of $8.6 \%$.

From the Ministry of Education of the People's Republic of China, we can learn that the scale of international students

\footnotetext{
* Corresponding author
}

continues to expand, the total number of students studying abroad in 2016 was 544,500 . The number of international students who comes to China reached to 440,000 , moreover China has become the largest international student exporting country in the world and the largest study abroad destination country.

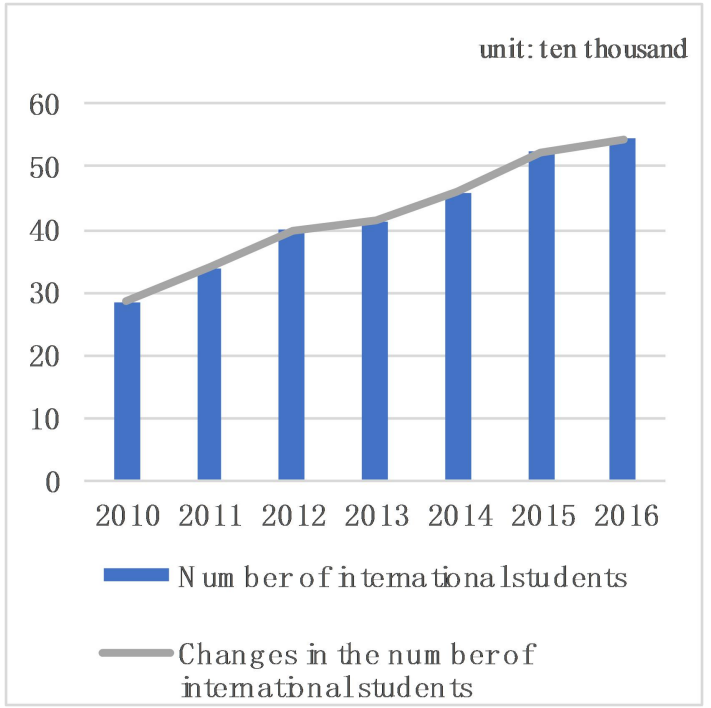

Fig. 1. From 2010 to 2016, the trend of Changes in the Number of Chinese international students

There are many Chinese students go for overseas internship, these Southeast Asian countries become the primary choice of these Chinese students. For example, International Business School of Yunnan University of Finance and Economics, since 2011, each year the International Business School send the students to Southeast Asian countries for internship, these countries include Thailand, Vietnam, Laos, India, Sri Lanka and so on. Nearly three months of overseas experience, they can fully understand the difficulties and challenges they encountered, and better adapt to overseas' study, work and life. This article focuses on the influence of cultural intelligence and cultural distance on overseas practice. 
Therefore, this paper chooses these overseas internships of students to study the factors between cultural distance and cultural intelligence.

In the case of assignments, as individuals enter foreign countries, they are immediately asked to deviate from the accustomed behaviour reflected in the local culture to adapt to the new cultural heritage [1]. Students often face work and non-working environments that involve cultural differences which test their ability to function effectively in new situations. The problem, however, is that when faced with "other people", culture or ethnicity, as students sometimes are not sure how to deal with their own original values and self-concept.

Four dimensions of cultural intelligence were covered in this paper to represent individual differences, and suggest to measure Cultural Distance's asymmetry effects, and further the cross-cultural adaptation model. Anderson (1994) [2] Besides social-cultural experience, we also expand both the model of cultural intelligence and cross-cultural adaptation through testing psycho-cultural experience construct [9].

\section{B. Overseas Internship}

When students who going overseas for internship step into foreign settings, in order to adjust to new cultural repertoires Ang and Van Dyne (2008) [3], they have to deviate from accustomed behaviour reflected in their native culture. Actually, those students who go for overseas internship, sometimes don' t know how to deal with their innate value orientations and self-concept rooted in their mind when they faced to the 'otherness' of people.

There will be many problems students will meet, such as non-experience, remain ineffective or return early from their overseas internship. The reasons why they encounter these problems are classified into the following aspects: (i) difficulties with new assignment, (ii) homesickness, (iii) inadequate living conditions (iv) inability to cope with larger overseas responsibility, (v) languages barriers, and(vi) communications problems.

When considering the reasons addressing student failure, a key reason and critical factor which has a closely connection with students' ineffectiveness is cross-cultural experience. Thus, we should put amount of attention on identifying the factors that influence cross-cultural experience.

\section{Cultural Intelligence}

Cultural Intelligence (CQ) is kind of individual nature that as to someone's ability to adapt effectively to a new cultural background Berry, Segall, and Kagitcibasi (1999) [4]. This kind of conceptualization mainly focuses on a specific domain of intelligence, as to intelligence in intercultural settings.

On the concept, emotional intelligence (EQ), social intelligence (SQ) and general mental ability (GMA) overlaps cultural intelligence, for that they complement intelligence (IQ), and it's important for individuals to work effectively and be effectively when faced with various social settings and in personal relationships aspect.
EQ and SQ describe the ability of individuals to manage emotions and interpersonal situations in a common cultural context. In other words, EQ and SQ lack cultural elements. Elenkov and McMahan (2005) [5]. Thus, they are less informative, so the individual's cognitive, motivational and behavioral predictions in the cultural diversity environment are less. Because social norms and value systems vary from culture to culture, individuals with high EQ and SQ in one culture cannot automatically change these abilities into a different cultural setting, because in a culture which is meaningful may not apply to another.

Besides, CQ is based on the theory of multiple intelligence, and is classified into a four-facet model, includes; (i) meta-cognitive, (ii) cognitive, (iii) motivational, and (iv) behavioural dimensions. These CQ's four factors as a sophisticated, mufti-factors individual attribute reflects the contemporary views of intelligence Hofstede (1980) [6].

More importantly, in individuals, with the development of cultural intelligence, it has produced expected profits of cross-cultural experience, and it has a gradually evolution on the past decades. These individuals or organizations who can recognize and realize the cultural intelligence's value are more likely achieve a competitive advantage through using the cultural differences. As a new research field, cultural intelligence getting more and more scholars and practitioners' attention.

\section{THEORETICAL DEVElopMENT}

Different family and host cultures play a critical role in the overseas internship experience. It should be note that many research about students' overseas internship experience potentially has a familiar theoretical positioning assumption which shows increasing the cultural difference between host and home culture, such as 'cultural distance'(CD) will increase experience difficulties.

However, this orientation depends on the symmetrical hypothesis of cultural distance. That is to say, by using "distance" as a predictor of experience, the literature ignores the direction of experience required for overseas internships.

Based on the theory of multiple intelligence, CQ mainly focuses on the specific areas of human intelligence, that is, intercultural settings in the cross-cultural environment. Cultural intelligence argues that individuals are different in terms of cultural adaptability, and because of the strong and comprehensive theoretical basis of individual differences, their patterns are particularly suitable for representing individual differences in students. As for different individuals have different capability, CQ shows that what someone could do something effectively when they in a diversity cultural environment. Therefore, it is different from the stable personality traits, it describes what the people usually does across time and across situations.

In contrast, the research records of eastern developing countries in the area of business activities are relatively weak and not systematic. The possible explanation for this is that students' overseas internships traditionally tend to move from affluent and developed countries to poor and developing 
countries, just as the Chinese students choose those Southeast Asian countries for their overseas internship place. However, in recent decades, the flow of students' overseas internships has become increasingly global and multifaceted.

Even so, for the opposite case, that is, students' internship in the West, such studies are almost non-existent, at least in English language. Especially, there are little attention were put on the relevant literature to examine the cross-cultural experience of Chinese students working in Thailand. It has been proposed to expand the scope of research in terms of geography and society by studying the relatively under-researched group of Chinese students practicing in Thailand. This can provide a broader research base to further enhance our understanding of the successful cross-cultural experience of overseas internships.

\section{CONCEPTUAL MODEL}

In a study conducted by Ang, Van Dyne, Koh and Ng (2003) [3], as described above, the four-factor cultural intelligence scale \{(i) cognitive, (ii) motivational, (iii) metacognitive, and (iv) behavioural) $\}$ was identified as a sample a group of domestic students. These results were subsequently confirmed in an empirical study by Ang, providing evidence for the construction and external validity of CQS for Singapore and US samples (student internships).

Although the research results are encouraging, and the construction and evaluation of CQ is more novel. In this sense, further examination of the situation (in this case, India and Thailand and some other Southeast Asian countries) can challenge the geographical limits of the model. In addition, through the participants to adapt to the target culture of reciprocal transfer, will form a relatively clear and may be more complete image, so it may affect each other in cultural distance on personal differences and cross-cultural experience.

In addition, the influence of cultural distance on the interaction between individual differences and cross-cultural experiences should be more clearly visible by including the mutual transfer of participants adapting to the target culture.

Early research, by using students as a sample or data set, takes into account the efficacy of CQ, basically assuming that students who conduct overseas internships go through same levels; As well as the same difficulties, experience and development stages as students have experienced. The plan sampling method of this study should provide a more informed validation of $\mathrm{CQ}$, thus extending the self-report questionnaire (CQS) results which has been wildly used in measuring $C Q$, its effectiveness and reliability need to be further considered [7]. This study will also make an important contribution to the cause-and-effect relationship between the variables.

The increasingly evident need is that if we want to fully understand the student internship experience process, a comprehensive or multidimensional approach is essential. Therefore, the general research question to promote this study is to investigate whether individual differences are related to cross-cultural experience and how cultural heterogeneity works in the relationship between cultural intelligence and student internship experience.

Students' overseas internship experience can be viewed in two different ways: (i) psycho-cultural experience and (ii) social-cultural experience. These two aspects are theoretically interrelated, but have different nuances. Socialcultural experience refers to the willingness and ability of individuals to participate, adapt or interact effectively with each other in host countries. In the culture of the host country, this experience involves the maintenance and smooth process of cultural learning, behavioural competence and the acquisition of social skills, including the ability to operate successfully on the job, to adapt to the living conditions, and to interact well with people in designated countries [8].

The concept of this experience comes from the theory of cultural learning, emphasizing the social behaviour and practical social skills of attitudes and strategies, and was adopted in previous studies on the process of the ability of individuals to function in different cultures. In contrast, psycho-cultural experiences are related to individual mental state and potential health in a new cultural context [9]. It focuses on attitudinal factors in the empirical process that can be measured by assessing the psychological symptoms and perceived pain of self-reporting [9]. In spite of this, as a study point, these two important sets of empirical variables, social-cultural and psycho-cultural experiences, have not been fully explored for their far-reaching business signification.

For the related literature, most of the research focused on the correlation between CQ and social-cultural experience, and the research on the relationship between CQ and psycho-culture is less. A recent study found that there was a positive relationship between motivational CQ and social-cultural experience, general life experience, and host country interaction experience. Further research is necessary to determine whether the student's psychological and cultural experience has the same relationship, and whether the students living in the collectivist culture of individualistic culture are real.

We predict that cultural distance will have a profound impact on cultural experience, and that people with higher cultural levels will have a higher level of social-cultural experience and a sense of happiness in psychological culture.

\section{CONCLUSIONS}

In view of the problem of cross-cultural students' overseas internship experience, this paper explores the theoretical model of cultural difference asymmetry and tests the impact of CQ on student experience, and puts forward the potential influence of CQ in individual difference under the cross-cultural background. More specifically, we examine the main problem of Cultural Distance and its connection with meta-cognitive, cognitive, motivational and behavioural factors of cultural intelligence relating to crosscultural experience. 
Globalization has contributed to the rapid growth of labour mobility over the past decade, and this liquidity will not slow down in the foreseeable future. By narrowing the disparity in our comprehension of how individual difference represented by cultural intelligence and cross-cultural experiences, the occurrence process may benefit [9]. Therefore, this study contributes to cross-cultural research and extends the pattern of cultural intelligence by further explaining the importance of individual differences in the cross-cultural experience.

The propositions raised in this paper may help improve students' willingness and people-to-people bonds. They indicated that these kinds of workshops assisted them in gathering more detailed information about the country they are going to. Through this article, students become more aware of the cultural differences and possible culture shocks they may face, learn how to solve relevant problems and thus can better adapt to overseas work and local life.

\section{ACKNOWLEDGMENT}

Funding for this research was provided by National Natural Science Foundation of China under grants 71762033. The facilitation from international collaborative program and cooperation with Charles Sturt University in Australia is gratefully acknowledged. The assistance of Dr. Eshref Trushin, Professor Mark Frost and Antony Bush and comments from an associate editor and two anonymous reviewers are also acknowledged.

\section{REFERENCES}

[1] J,M. Harzing, "Global leadership success through emotional and cultural intelligences,” Business Horizons, vol. 48, 2009, pp. 501-512.

[2] L.E. Anderson, "A new look at an old construct: Cross-cultural adaptation,” International Journal of Intercultural Relations, vol. 18, 1994, pp. 293-328.

[3] S. Ang, and L. Van Dyne, "Conceptualization of cultural intelligence: Definition, distinctiveness, and nomological network," In S. Ang and L. Van Dyne (Eds.), Handbook on cultural intelligence: Theory, measurement and applications, 2008, pp. 3-15.

[4] J.w. Berry, M.H. Segall, and C. Kagitcibasi, "Handbook of crosscultural psychology," Social behavior and applications. Boston: Allyn and Bacon, vol. 3, 1990.

[5] P.C. Earley and R.S. Peterson, "The elusive cultural chameleon: Cultural intelligence as a new approach to intercultural training for the global manager," Academy of Management Learning and Education, vol. 3, 2004, pp. 100-115.

[6] D.S. Elenkov and C. McMahan, "Investigating the role of cultural intelligence on the effect of executive leadership on marketing innovation in a multi-cultural context," Journal of International Business and Economics, vol. 3, 2005, pp. 19-23.

[7] G. Hofstede, "Culture's Consequences: International Differences in Work-Related Values," 2008.

[8] G.K. Stahl, and P.M. Caligiuri, "The effectiveness of student coping strategies: The moderating role of cultural distance, position level, and time on the international assignment," Journal of Applied Psychology, vol. 90, 2005, pp. 603-315.

[9] C. Ward and A. Kennedy, "Crossing cultures: the relationship between psychological and socio-cultural dimensions of crosscultural experience," 1996. 